\title{
Análise de Solvência do Regime Geral da Previdência Social no Brasil
}

\author{
Paulo Rogério Faustino Matos
}

Professor - Universidade Federal do Ceará (CAEN)

Endereço para contato: Av. da Universidade, 2700, $2^{\circ}$ andar, Benfica - Fortaleza - Ceará

CEP: 60020-181 - E-mail: paulomatos@caen.ufc.br

\section{Fabíola de Souza Pinto Melo}

Assessora - Caixa de Previdência dos Funcionários do Banco do Nordeste do Brazil (CAPEF) Endereço para contato: Av. Sanos Dumont 771, Centro - Fortaleza - Ceará

CEP: 60150-160 - E-mail: fabiola.souza@capef.com.br

\author{
Andrei Gomes Simonassi \\ Professor - Universidade Federal do Ceará (CAEN) \\ Endereço para contato: Av. da Universidade, 2700, $2^{\circ}$ andar, Benfica - Fortaleza - Ceará \\ CEP: 60020-181- E-mail: agsimonassi@gmail.com
}

Recebido em 14 de agosto de 2012. Aceito em 13 de dezembro de 2012.

\section{Resumo}

Este artigo agrega ao debate sobre a solvência do Regime Geral da Previdência Social (RGPS) no Brasil, um sistema de repartição simples cujos parâmetros divergem dos padrões internacionais em termos demográficos, econômicos e sociais. Seguindo principalmente a metodologia de Bohn $(1998,2007)$, evidencia-se, durante o período de janeiro de 1990 a dezembro de 2010, que o saldo previdenciário do RGPS apresenta quatro distintos regimes, sendo apenas um deles caracterizado como insolvente, durante abril de 1994 e outubro de 1997, possivelmente associado aos efeitos do advento da Lei $n^{\circ} 8.213 / 91$. Ao contrário do que diversas análises apontam sobre a situação da previdência social brasileira, os resultados sugerem não ser explosiva a trajetória recente de déficits, sendo inclusive possível identificar uma melhoria a partir de outubro de 2006, em resposta ao encerramento da primeira fase do Censo Previdenciário e a criação do Super Simples. Apesar da preocupação da sociedade com o registro de sucessivos déficits mensais, a participação governamental neste regime tem representado parcelas menores do Produto Interno Bruto, sendo esta sinalização de solvência relevante na condução de políticas públicas associadas à previdência. Este cenário otimista, porém, não invalida a necessidade de reformas no sistema, tendo em vista a eficiência das intervenções do Governo no sentido de controlar o quadro deficitário do RGPS.

\section{Palavras-Chave}

Regime Geral da Previdência Social no Brasil, sustentabilidade fiscal, arcabouço de resposta fiscal, reforma previdenciária 


\begin{abstract}
This article contributes to the debate on the solvency of the General Social Security System (RGPS) in Brazil, a simple distribution system whose parameters differ from international standards in terms of population, economy and social aspects. Following mainly the methodology of Bohn $(1998,2007)$, we can evidence that, during the period from January 1990 to December 2010, the RGPS social welfare balance has four distinct regimes, with only one of them characterized as insolvent, during April 1994 and October 1997, associated with the effects of the enactment of Law No. 8.213/91. Unlike several studies argue about the situation of the RGPS, the results suggest a recent non-explosive trend for Brazilian social security system, especially the period after October 2006, in response to the closure of the first phase of the census and the creation of Super Simple. Thus, despite the concern of society regarding the successive monthly deficits, the government participation in the scheme has represented smaller shares of GDP, a relevant signaling solvency to implementing public policies associated with social welfare reform. However, this conclusion does not invalidate the need for adjustments to the system, since reaction from the government are effective in order to control the deficit of the social security.
\end{abstract}

\title{
Keywords
}

General Regime of Social Security in Brazil, fiscal sustainability, fiscal response framework

\section{JEL Classification}

$\mathrm{H} 55, \mathrm{H} 63$

\section{Introdução}

A racionalidade e o aspecto desejável acerca de preferências bem comportadas de agentes econômicos implicam uma trajetória ótima suavizada de consumo intertemporal de bens e serviços diante dos possíveis estados incertos da natureza. Sob essa premissa básica em modelagens que envolvam teoria do consumidor e diante de cenários incertos e de longo prazo caracterizados por contingências sociais tais como velhice, desemprego, invalidez, os agentes se viram motivados a criar instrumentos de proteção ao indivíduo, resguardando seu sustento e minimizando os efeitos econômicos negativos sobre as famílias.

A sociedade compreendeu que os resultados associados à alocação de recursos escassos eram mais eficientes quando os esforços de proteção e de produção partiam de uma associação de indivíduos, em vez de recorrerem, por exemplo, à família, primeira forma de organização social de assistência. Neste contexto foram instituídos arranjos securitários baseados no mutualismo que evoluíram para o 
sistema previdenciário, como conhecido atualmente. ${ }^{1}$ Para Oliveira et al. (2000), a Previdência Social objetiva aos seus beneficiários meios indispensáveis de manutenção, por motivo de incapacidade, idade avançada, tempo de serviço, desemprego involuntário, encargos de família e reclusão ou morte daqueles de quem dependiam economicamente.

Em razão da complexidade dos cálculos das rubricas de arrecadação e despesa, e motivado pela dependência não trivial de tendências econômicas, sociais e demográficas, evidencia-se, principalmente nas três últimas décadas, uma evolução no sistema previdenciário de várias economias, caracterizada por reformas paramétricas e estruturais, a qual tem sido acompanhada pela literatura atuarial, financeira e econômica.

Atendo-se à relação entre a estrutura demográfica, aspectos laborais e despesas previdenciárias, segundo a análise reportada em Caetano (2006), dentre 52 países pesquisados, o Brasil possui percentual de contribuintes na força de trabalho inferior a mediana internacional e valor médio da aposentadoria em relação à renda per capita equivalente a 59,4\%, enquanto a média internacional se situa em 48,3\%. Ainda de acordo com este autor, países com características demográficas similares às brasileiras despendem com previdência algo em torno de $4 \%$ do respectivo Produto Interno Bruto (PIB).

Corroborando estes resultados, Giambiagi et al. (2007) analisam para vários países a relação entre a proporção de pessoas acima de 65 anos na população do país e o percentual do PIB gasto com benefícios previdenciários, evidenciando um padrão baseado na correlação positiva, com exceções pontuais. Enquanto o Japão possui gastos de aproximadamente $10 \%$ do PIB, nível bastante inferior ao previsto com base no elevado percentual de sua população com mais de 65 anos, $18 \%$, economias como a mexicana e brasileira, cuja estrutura etária é caracterizada por possuir de $5 \%$ a $6 \%$ da população com mais de 65 anos, alocam com a previdência, respectivamente, $8 \%$ e $11 \%$ do PIB, níveis semelhantes ao de países europeus com população mais envelhecida e de extensa rede de proteção social, como Holanda, Reino Unido e Espanha.

1 Historicamente, as primeiras tentativas de implantação de regimes securitários datam do século XVII, sendo editada em 1601, na Inglaterra, a Lei dos Pobres Londrina, instituindo o primeiro normativo previdenciário. 
Consequentemente, segundo Caetano \& Miranda (2007), em um ranking de despesas previdenciárias como proporção do PIB, o Brasil ocupa a $14^{\text {a }}$ posição de um total de 113 economias analisadas.

Adicionalmente, observando o histórico da previdência brasileira, evidencia-se que em razão da má aplicação dos recursos arrecadados na década de 50 não se conseguiu manter o sistema capitalizado, implicando a adoção do sistema de repartição simples, praticado atualmente e tido como inadequado frente às mudanças demográficas, econômicas e sociais.

Vários países têm tido dificuldades em manter em equilíbrio este tipo de sistema de previdência baseado na solidariedade intergeracional, havendo consequentemente uma sucessão de reformas nos sistemas de seguridade social. Na América Latina, alguns exemplos são o Chile em 1981, o Peru em 1993, a Colômbia e a Argentina em 1994, o Uruguai em 1996, a Bolívia e o México em 1997, El Salvador em 1998 e a Costa Rica em 2001. Diante deste cenário, verifica-se que o Brasil adota um regime inadequado para sua realidade, apresenta indicadores fora dos padrões internacionais, possui regras generosas aliadas à incompatibilidade demográfica e ao baixo esforço contributivo, ao mesmo tempo em que repõe parcelas elevadas da renda. Um panorama tão custoso do ponto de vista fiscal exige a adoção mandatória de medidas em esforço mútuo por parte do Estado. Este contexto justifica a relevância de se estudar a sensibilidade das fontes de receitas e despesas em razão de fatores influentes, de se mensurar impactos de reformas implementadas, ou ainda de se analisar a solvência da trajetória do déficit previdenciário.

Nesse sentido, o artigo contribui com a discussão sobre a sustentabilidade da previdência no Brasil, mais especificamente do Regime Geral de Previdência Social, durante o período de 1990 e 2010, seguindo metodologicamente Hamilton \& Flavin (1986), Hakkio \& Rush (1991), Bohn (1991, 1998, 2007), arcabouços estes mais comumente utilizados no estudo sustentabilidade da dívida pública.

O artigo está dividido em cinco seções. Além desta introdução, a seção 2 aponta os aspectos teóricos envoltos no conceito da previdência social, seu histórico e a literatura relacionada para o caso brasileiro. A sessão 3 apresenta a metodologia, enquanto na quarta seção são 
discutidos os resultados do exercício empírico. A seção 5 apresenta as considerações finais.

\section{Previdência Social no Brasil}

\subsection{Um histórico de Cenários Deficitários}

O caráter obrigatório de filiação da previdência deve ser visto como um contrato entre os cidadãos e o Estado, o qual firma a manutenção de condições mínimas de sobrevivência mediante o apoio solidário de todos frente às necessidades de alguns. Porém, diferentemente da assistência social, a previdência corresponde a uma forma de seguro social, originando, como qualquer outro seguro, sua característica contributiva. Este aspecto define a necessidade da participação financeira direta do segurado para a fundação dos benefícios, seja de modo individual ou coletivo, a depender do regime financeiro adotado. Sobre os tipos destes regimes, os quais instituem o modo de acumulação dos recursos garantidores dos benefícios, no Sistema de Repartição Simples tem-se a solidariedade entre gerações de empregados, no de Capitalização, as atuais contribuições são destinadas à acumulação de reservas responsáveis pelo pagamento futuro das aposentadorias e pensões e no Regime de Capitais de Cobertura, a cada exercício, são fundados os recursos garantidores dos benefícios concedidos neste determinado período. ${ }^{2}$

A história da previdência no Brasil possui no amparo estatal aos empregados em 26 de março de 1888, um de seus marcos iniciais, quando se regulamentou a aposentadoria dos trabalhadores dos Correios, através do Decreto 9.912-A. Contudo, o processo previdenciário brasileiro estabeleceu-se formalmente em 24 de janeiro de 1923, com a aprovação do Decreto Legislativo $n^{\circ} 4.682$, Lei Eloy Chaves, que determinou a criação das Caixas de Aposentadorias e Pensões (CAPs) para os empregados de empresas ferroviárias, oferecendo assistência médica e cobrindo riscos de invalidez, velhice e morte. Na década de 30 , o sistema foi ampliado para abranger novas categorias profissionais através das figuras dos Institutos de Aposentadorias e Pensões (IAPs). O Decreto 22.872, de 29 de junho de 1933, organizou o IAP

2 Segundo Ramos (2003), "trata-se de um método de capitalização terminal, cujas reservas são capitalizadas no período em que o benefício é concedido". 
dos Marítimos, primeiro de esfera nacional. Baseada inicialmente em regimes capitalizados, a previdência no Brasil era utilizada como fonte de financiamento para diversos setores da economia. Segundo Oliveira et al. (1999), muitos recursos dos institutos foram investidos em hospitais e ambulatórios, na Companhia Vale do Rio Doce, na Companhia Hidroelétrica do Vale de São Francisco, bem como na construção de Brasília. O baixo rendimento das aplicações, associado ao não pagamento da cota de responsabilidade da União, a sonegação por parte dos empregadores e o processo inflacionário, impossibilitaram, já na década de 1950, a manutenção deste sistema capitalizado, o que ocasionou a adoção do sistema de repartição simples, praticado até hoje, porém, considerado inadequado em razão de mudanças demográficas, econômicas e sociais.

Em 1960, a Previdência Social foi realmente institucionalizada através da Lei 3.807, Lei Orgânica da Previdência Social (LOPS), em que se padronizou o sistema assistencial e unificou as normas referentes aos IAPs. Na sequência, o direito aos benefícios foi estendido aos trabalhadores rurais através da Lei 4.214, em que foi criado o Fundo de Assistência ao Trabalhador Rural (FUNRURAL) e em 1965, foi criado o Instituto Nacional de Previdência Social (INPS).

A constituição de 1988 representou o último marco em direção à implantação da cobertura previdenciária universal, além de ter trazido um conceito mais abrangente de proteção social, o da Seguridade Social, apoiada em seus três alicerces: previdência, assistência social e saúde. Adicionalmente, o novo normativo estabeleceu uma diferenciação entre os regimes que abrangem os trabalhadores da iniciativa privada, amparados pelo Regime Geral de Previdência Social (RGPS), e os servidores públicos, representados pelo Regime Jurídico Único. ${ }^{3}$

A partir de então, verificou-se uma deterioração das contas previdenciárias que culminou com o déficit em 1995, persistindo até os dias atuais. Instrumentos legais foram aprovados no sentido de conter o avanço das necessidades de financiamento do sistema e de reverter o

3 Atualmente, além dos trabalhadores da iniciativa privada, o sistema previdenciário alcança também os informais, através do RGPS, enquanto os servidores públicos de cargo efetivo das diversas esferas são amparados pelos Regimes Próprios de Previdência Social (RPPS), observados os casos em que os servidores não possuam previdência própria, hipótese em que serão acolhidos pelo RGPS. Os Regimes Próprios oferecem proteção social aos servidores públicos efetivos, ou seja, servidores de carreira permanentes. Em 2007, eram contabilizados regimes próprios instituídos em 2.200 Municípios e 26 Estados, Distrito Federal e União. 
processo de expansão do déficit, tais como a Emenda Constitucional $n^{\circ} 20$ de 1998 e a Lei Complementar n. ${ }^{\circ}$ 9.876/99, normativos que surgiram com a finalidade de imprimir ações inibidoras à concessão de benefícios sem sua devida fonte de custeio e à aposentadoria precoce. Ao tempo em que o estado vai intervindo no sistema previdenciário, a sociedade vai evoluindo em termos demográficos, sendo necessário destacar o forte processo de envelhecimento, o aumento progressivo da longevidade e as baixas taxas de natalidade, os quais ocasionam a diminuição da base de financiamento e o aumento das despesas com benefícios.

Enquanto na década de 1940 registrava-se mais de 30 contribuintes por beneficiário, esta proporção reduz a 5 para 1 na década seguinte e depois para menos de 3 para 1 já no início dos anos 80 , sendo este o patamar atual. Acrescido a este fator, o alto grau de informalidade registrado durante anos, a ampliação da cobertura sem apropriada fonte de custeio e a concessão de aposentadorias precoces têm influenciado o surgimento do déficit previdenciário, motivando as discussões sobre o equilíbrio do RGPS.

A Tabela 1 reporta algumas estatísticas descritivas sobre aspectos populacionais no Brasil.

Tabela 1 - Estatísticas descritivas das principais séries macroeconômicas e previdenciárias ${ }^{\mathrm{a}, \mathrm{b}}$

\begin{tabular}{ccccc}
\hline Métrica & $\begin{array}{c}\text { Despesa com benefícios/ } \\
\text { População economica- } \\
\text { mente ativa }\end{array}$ & $\begin{array}{c}\text { População ocupada com } \\
\text { carteira assinada/ População } \\
\text { economicamente ativa }\end{array}$ & Salário mínimo & $\begin{array}{c}\text { Proporção de } \\
\text { idosos }\end{array}$ \\
\cline { 2 - 5 } & $\begin{array}{c}\text { Unidade: } \mathrm{R} \$ \text { constantes } \\
\text { de dez/2010, com base } \\
\text { no INPC) }\end{array}$ & Unidade: $\%$ & $\begin{array}{c}\text { Unidade: } \mathrm{R} \$ \text { cons- } \\
\text { tantes de dez/2010, } \\
\text { com base no INPC) }\end{array}$ & Unidade: \% \\
\hline Mínimo & $\mathrm{R} \$ 147,43$ & $37,85 \%$ & $\mathrm{R} \$ 144,92$ & $6,70 \%$ \\
Média & $\mathrm{R} \$ 581,63$ & $44,35 \%$ & $\mathrm{R} \$ 328,90$ & $8,33 \%$ \\
Máximo & $\mathrm{R} \$ 1.314,13$ & $57,87 \%$ & $\mathrm{R} \$ 538,24$ & $11,07 \%$ \\
Taxa de & $3,62 \%$ & $-0,06 \%$ & $1,07 \%$ & $0,17 \%$ \\
$\begin{array}{c}\text { Desvio padrão } \\
\text { Coeficiente de } \\
\text { variação }\end{array}$ & $\mathrm{R} \$ 238,95$ & $4,05 \%$ & $\mathrm{R} \$ 94,71$ & $1,07 \%$ \\
\hline
\end{tabular}

${ }^{a}$ Valores das rubricas previdenciárias expressos em reais constantes, atualizados pelo INPC mensal, a preço de dezembro/2010 (série temporal de janeiro de 1990 a dezembro de 2010, 252 observações mensais). ${ }^{\mathrm{b}}$ Fonte: Ministério da Previdência Social (MPS) e Instituto Brasileiro de Geografia e Estatística (IBGE). 
Em termos demográficos, há uma constatação preocupante no que se refere à população economicamente ativa que possui carteira assinada, a qual apresenta taxa negativa de crescimento, mesmo que pequena e motivada, principalmente pelos dados dos primeiros anos da amostra. É possível identificar uma taxa expressiva de crescimento no ano de 2010, 0,53\%. Já se observando os últimos 5 anos, o crescimento médio seria de $0,27 \%$. Já a proporção de idosos evolui a uma taxa de $0,17 \%$ ao mês, de forma que o Brasil já ultrapassa o patamar de $10 \%$ da população com mais de 60 anos.

A evolução do salário mínimo, apesar de estar associada a um maior bem-estar social e redução de indicadores de pobreza e desigualdade, também parece preocupante, pois indica um crescimento superior a $1 \%$ mensais acima da inflação, uma vez que todos os dados reportados são reais, ou seja, deflacionados. Estas simples evidências, as quais podem ser sumarizadas pelo crescimento mensal de 3,62\% do gasto previdenciário por população economicamente ativa, parecem justificar a preocupação em relação à evolução, previsão e sustentabilidade no longo prazo do sistema previdenciário brasileiro.

A Figura 1 retrata a evolução dos resultados anuais do RGPS a partir de 1990. Com base na evolução plotada nessa figura, nota-se uma tendência de redução do saldo previdenciário, o qual passa a registrar valores negativos a partir de 1995, chegando a contabilizar valores 60 vezes maiores do que há 15 anos. Este cenário se deve ao ritmo lento da expansão da arrecadação associado ao rápido crescimento das despesas com benefícios do RGPS, fomentado principalmente com o advento da Lei $n^{\circ} 8.213 / 91$, em que se determinou a padronização dos benefícios urbanos e rurais.

Atendo-se aos valores mensais somente de 2010, último ano da amostra, tem-se um saldo previdenciário médio negativo da ordem de $\mathrm{R} \$ 3,7$ bilhões, associado a um nível de gastos com benefícios previdenciários da ordem de $6,9 \%$ do PIB, bastante elevado, considerando-se o percentual da população com mais de 65 anos abaixo de $8 \%$. Este cenário tem motivado o debate acadêmico e político sobre as principais fontes de arrecadação e despesa, impactos de reformas paramétricas e estruturais, e da solvência do sistema. 


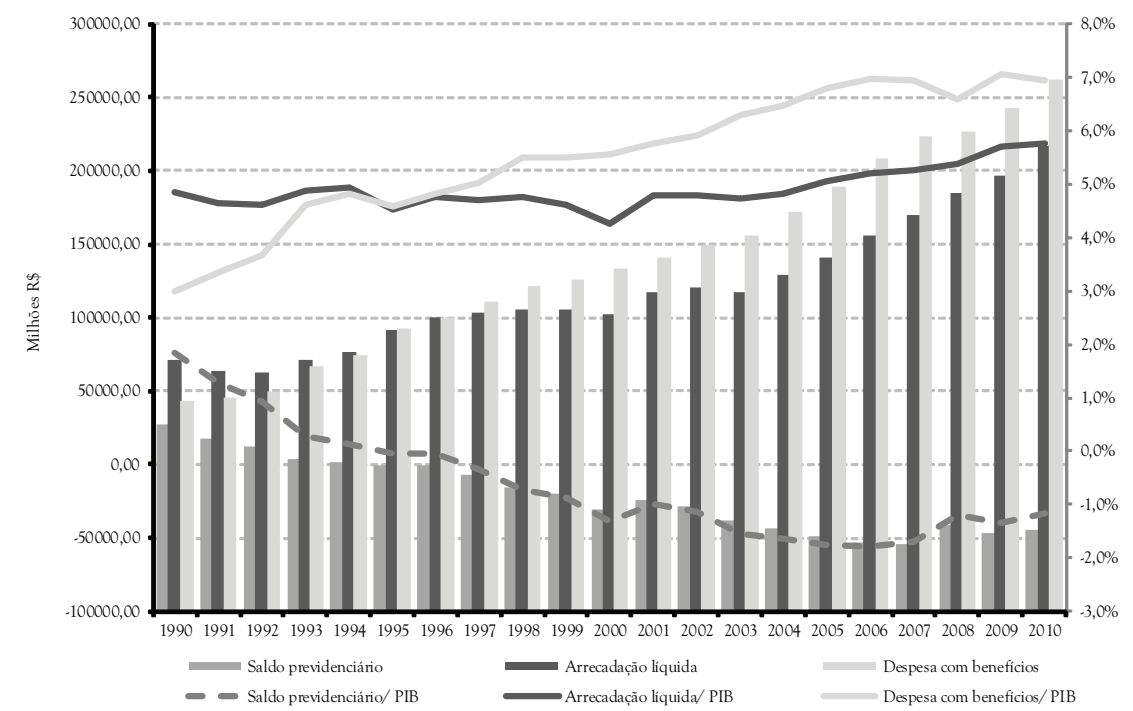

Figura 1-RGPS: Evolução do saldo previdenciário, da arrecadação e de despesas ${ }^{\text {a, b }}$

a Valores das rubricas previdenciárias e do PIB expressos em reais constantes, atualizados pelo INPC mensal, a preço de dezembro/2010 (série temporal de 1990 a 2010, 21 observações anuais). ${ }^{b}$ Fonte: Ministério da Previdência Social (MPS) e Banco Central do Brasil (BACEN).

\subsection{Literatura Relacionada}

Motivado pelo dinamismo de tendências econômicas, sociais e demográficas e suas consequências, evidencia-se, principalmente nas três últimas décadas, uma evolução no sistema previdenciário de várias economias caracterizada por reformas paramétricas e estruturais. Este avanço tem sido acompanhado gradualmente pela literatura atuarial, financeira e econômica. Recentemente, Caetano \& Miranda (2007) comparam os gastos previdenciários entre diversos países através do método Data Envelopment Analysis (DEA). A técnica procura definir um ranking de quanto o país despende com previdência, após controlar os efeitos das variáveis que influenciam o gasto. Os resultados mostram que o Brasil encontra-se no topo do ranking entre os países nos quais o sistema previdenciário é superdimensionado. Alinhado a este artigo, Tafner (2007) analisa as regras de elegibilidade e concessão, concluindo que, dentre o universo considerado, o Brasil é o país que possui regras menos restritivas. 
Atendo-se ao Brasil e às reformas previdenciárias, Oliveira, Beltrão \& Pasinato (1999) analisam o período após a aprovação da Emenda Constitucional $n^{\circ}$ 20/98. Os autores reconhecem sua importância, porém enfatizam a insuficiência de suas medidas em deter a trajetória do déficit previdenciário, cuja projeção atingiria $14 \%$ do PIB em 2030. Os autores sugerem um novo modelo de Regime Único para a iniciativa privada e os servidores públicos, sendo estabelecidas alíquotas atuarialmente justas em função das características do segurado. Ainda sob este contexto constitucional, Oliveira et al. (2000) estimam os impactos econômico-financeiros desta Emenda, assim como do fator previdenciário no déficit da previdência para o período entre 2000 e 2030, sendo possível mensurar as expressivas reduções, as quais, no entanto, seriam insuficientes, havendo a necessidade de futuras reformas. Esta necessidade é corroborada em Mascarenhas, Oliveira \& Caetano (2004) e Souza et al. (2006), mesmo após os impactos fiscais advindos da reforma na previdência dos servidores públicos durante o Governo Lula. Giambiagi et al. (2007) quantificam o impacto de reformas paramétricas na previdência social brasileira através de simulações de cenários, sendo os efeitos mensurados pelo valor presente e pelo fluxo de longo prazo do saldo previdenciário. A comparação dos cenários sinaliza para a necessidade da interrupção dos ganhos reais do piso previdenciário e adoção de idade mínima de aposentadoria.

Sob uma ênfase econométrica de modelagem do saldo previdenciário, Dantas, Ataliba \& Matos (2012) identificaram um conjunto de fatores influentes nas receitas e despesas com benefícios do RGPS e concluíram sobre a importância do mercado de trabalho formal, de características demográficas, do reajuste do salário mínimo e do nível do PIB. Há ainda a projeção do saldo previdenciário, considerando diversos cenários. Estes resultados corroboram Leite et al. (2010).

Apesar do desenvolvimento da literatura no sentido de identificar fatores influentes nas contas previdenciárias, há ainda uma ausência na literatura brasileira de trabalhos que avaliem a tendência de suas trajetórias em termos de solvência. Especificamente sobre sustentabilidade, uma das poucas citações é Caetano (2006), o qual identifica os fatores de influência do custo e sustentabilidade através de um modelo matemático simplificado do equilíbrio financeiro de curto prazo da previdência, sendo proposto um indicador baseado na alíquota de contribuição, taxa de reposição e razão de dependência. 
Alinhado a Caetano (2006), em termos de objetivo geral, este artigo propõe a utilização de três técnicas que estudam a sustentabilidade da dívida pública de países, estados e municípios, porém aplicadas ao Regime Geral de Previdência Social, durante o período de 1990 a 2010. Em suma, a primeira testa a estacionariedade da série de saldo previdenciário, sendo a rejeição da hipótese de raiz unitária um indício de solvência do sistema da RGPS. A segunda testa a cointegração das séries de receitas e despesas, sendo a não rejeição desta hipótese um indício sobre o efeito de compensação nas trajetórias de longo prazo da receita e despesa, sugerindo sustentabilidade da dívida. Por fim, a terceira abordagem analisa a existência de uma reação positiva da série de superávit primário frente ao aumento da dívida no período anterior.

\section{Metodologia}

\subsection{Teoria Econômica: Sustentabilidade Fiscal}

O interesse por inferir estatisticamente sobre a solvência ou sustentabilidade da dívida de uma entidade governamental, a partir de séries temporais de receitas, gastos ou déficits, consiste em um mainstream em finanças públicas. A motivação para esta vertente acadêmica está associada à relevância da austeridade intertemporal na condução de política fiscal, monetária e cambial.

Uma vez que as economias, principalmente as desenvolvidas, passaram a primar por esta austeridade nos gastos a partir da década de 90 , esta literatura pode ser considerada recente, sendo possível identificar diferentes técnicas econométricas, todas, porém, fundamentadas em um mesmo conceito teórico: a restrição orçamentária intertemporal, como condição de equilíbrio a ser satisfeita de forma a se assegurar a solvência de uma política fiscal.

Assim, em uma economia com infinitos períodos, a restrição orçamentária em $t$ pode ser expressa da seguinte forma:

$$
B_{t}=\left(1+r_{t}\right) B_{t-1}+\left(G_{t}-R_{t}\right)
$$


Nesta relação, $B_{t}$ é o valor do estoque da dívida pública em $t, r_{t}$ consiste na taxa de juros incidente sobre a dívida pública em $t, G_{t}$ significa os gastos nominais do governo em bens e serviços (exclusive despesas financeiras, como pagamento de juros sobre a dívida) em t e $R_{t}$ representa a arrecadação nominal com impostos, contribuições e outras receitas em $t$.

Neste contexto intertemporal, havendo previsão perfeita, é possível associar o estoque inicial de dívida a um fluxo infinito descontado de receitas e despesas através da seguinte relação:

$$
B_{0}=\lim _{n \rightarrow \infty} \prod_{t=1}^{n}\left(\frac{1}{1+r_{t}}\right) B_{n}+\sum_{t=1}^{\infty}\left[\frac{R_{t}-G_{t}}{\prod_{j=1}^{t}\left(1+r_{j}\right)}\right]
$$

Como usual nesta literatura que adota fluxos futuros descontados por taxas de juros variáveis ao longo do tempo, assume-se que o governo não seja capaz de renegociar a dívida infinitas vezes, o que implica o valor nulo para o limite à direita da relação (2), reduzindo o equilíbrio intertemporal à seguinte relação, a qual modela o orçamento da entidade pública, caracterizando o equilíbrio caso o estoque da dívida em $t=0$ seja equivalente à soma do valor presente do fluxo sem incerteza dos superávits futuros:

$$
B_{0}=\sum_{t=1}^{\infty}\left[\frac{R_{t}-G_{t}}{\prod_{j=1}^{t}\left(1+r_{j}\right)}\right]
$$

Analisar estatisticamente se uma entidade governamental satisfaz esta relação simples e intuitiva pode ser conduzida através de várias formas.

Possivelmente, Hamilton \& Flavin (1986) tenham sido pioneiros no estudo da sustentabilidade fiscal do governo, ao propor testes de raiz unitária associados ao déficit orçamentário do governo americano durante o período entre 1960 e 1984. Uma extensão natural deste trabalho consiste em Hakkio \& Rush (1991), em que se analisa a sustentabilidade da economia americana para o período de 1950 a 1988, porém sobre o pressuposto de que restrição orçamentária intertemporal é obedecida quando se evidencia uma relação de cointegração entre a despesa fiscal, incluindo juros, e a arrecadação fiscal. 
Bohn (1991) corrobora conceitualmente esta argumentação sobre sustentabilidade de dívida pública. A sequência desta literatura se dá com Bohn (1998), o qual propõe uma forma alternativa de avaliação da sustentabilidade independente de qualquer condição sobre o comportamento da taxa de juros, intitulada função de reação fiscal, segundo a qual a restrição orçamentária intertemporal do governo passa a ser atendida, caso se evidencie uma reação positiva do superávit primário em $t$ em razão de elevações da relação dívida/PIB em $t-1$. Uma das principais críticas às vertentes anteriores de estacionariedade do déficit ou da cointegração das séries de despesa e arrecadação, segundo Bohn (2007), está no argumento de que a sustentabilidade pode estar associada à estacionariedade obtida a partir de qualquer número finito de diferenciações, havendo uma ampla classe de processos estocásticos que satisfazem a restrição orçamentária (3), mesmo sendo reprovados pelos testes de raiz unitária ou de cointegração.

Este conjunto de técnicas tem sido utilizado na análise de solvência principalmente de dívidas públicas associadas à condução de políticas fiscais de governos federais, estaduais e municipais em diversas economias. Atendo-se ao caso brasileiro, Pastore (1995) foi o primeiro a evidenciar a sustentabilidade da dívida em razão da política monetária vigente na época, que se valeu da senhoriagem como importante fonte de receita. Rocha (1997), Lupporini (2000), Garcia \& Rigobon (2004), Simonassi \& Arraes (2007) e Pereira (2008) agregaram a esta literatura empírica para a realidade brasileira, incorporando as inovações metodológicas. Em suma, estes estudos concluem que a dívida pública seja sustentável no longo prazo, desde que a senhoriagem seja considerada como parte da arrecadação, havendo, no entanto, resultados que sinalizem a insustentabilidade quando considerado o período pós-estabilização econômica.

\subsection{Teste Empírico da Função de Reação Fiscal}

As técnicas iniciais de análise de solvência possuem limitações. Com relação à primeira metodologia, por exemplo, a qual testa estacionariedade da série temporal de déficit, é possível que não haja robustez nas conclusões quando da mudança do teste utilizado. Alguns testes possuem baixa potência e os resultados podem ser inconsistentes em 
pequenas amostras ou na presença de quebras estruturais da série em questão. No caso da segunda, é possível que séries de arrecadação e despesas previdenciárias sejam integradas de mesma ordem, porém não cointegradas, e, ainda assim, o processo estocástico associado ao saldo previdenciário ser tal que seja atendida a condição de restrição orçamentária intertemporal (3).

Neste sentido, além dos testes de estacionariedade de cointegração, intitulados aqui como preliminares, este artigo propõe como principal exercício empírico a análise de solvência ou sustentabilidade de fluxos de receitas e despesas através da função de reação fiscal, seguindo metodologicamente Bohn $(1998,2007)$.

Esta metodologia possui em comum com as demais o referencial teórico. No entanto, este arcabouço, além de estar bem especificado econometricamente quando da presença de quebras estruturais e sazonalidade, também capta a resposta positiva ou negativa na geração de superávit primário no período corrente, dado de um choque na dívida pública no período anterior, agregando propriedades dinâmicas da dívida.

Formalmente, a adaptação da função de resposta fiscal de Bohn $(1998,2007)$, originalmente proposta para questões fiscais associadas a governos, para questões previdenciárias é definido pela seguinte relação:

$$
s p_{t}=\mu+\alpha e d p_{t-1}+\beta \widetilde{d p}_{t}+\gamma \widetilde{r p_{t}}+\varepsilon_{t}
$$

Em (4), $s p_{t}$ é o saldo previdenciário mensal em $t$, ou seja, consiste na arrecadação líquida previdenciária em $t, r p_{t}$, subtraída da despesa com benefícios previdenciários em $t, d p_{t}$. Em todos os testes realizados, estas variáveis previdenciárias são calculadas como razão do PIB. Já $\widetilde{r p}_{t}$ consiste no desvio das receitas previdenciárias em $t$, enquanto $\widetilde{d p}_{t}$ é o desvio das despesas previdenciárias em $t$. Estes desvios são em relação aos respectivos valores obtidos via filtro de Hodrick-Prescott, cujo parâmetro de suavização utilizado foi $\delta=14400$, comumente utilizado para dados em frequência mensal. ${ }^{4}$

4 Ver, por exemplo, Cusinato et. al. (2010).

Est. Econ., São Paulo, vol. 43, n.2, p. 301-333, abr-jun. 2013 
Uma atenção especial precisa ser dada à série $e d p_{t}$, a qual consiste no estoque da dívida previdenciária em $t$, como razão do PIB acumulado dos últimos 12 meses. Neste caso, a escolha por dados acumulados em 12 meses novamente se justifica pela literatura pré-existente na área de política fiscal, cujos principais estudos utilizam frequência anual. Cabe notar que a opção por dados acumulados, além de tornar a ponderação consistente dos dois lados da equação, evita eventuais problemas advindos de possível sazonalidade nos fluxos mensais. Ou seja, a série $e d p_{t}$ corresponde ao oposto da série de saldo previdenciário acumulado como proporção do PIB acumulado, variável definida neste trabalho como proxy para a real situação histórica da previdência no Brasil em termos fiscais. Em termos atuariais, não é usual acompanhar o passivo de um regime previdenciário que adote o sistema de repartição simples, caso em que não há mensuração de estoque da dívida. Porém, em termos econômicos, esta série equivale à dívida de um governo municipal, estadual ou federal, variável macroeconômica usualmente acompanhada por policy makers. Assim, a variável chave incluída neste arcabouço de resposta fiscal adaptada para solvência previdenciária adota a metodologia utilizada pelo Ministério da Previdência Social na apuração mensal do cálculo do saldo previdenciário acumulado.

Ademais, a utilização dos desvios das receitas e despesas previdenciárias segue de forma análoga ao que foi proposto em Uctum et. al. (2006) para uma abordagem aplicada à dívida pública em um mesmo contexto de múltiplas mudanças estruturais endógenas.

Com relação aos coeficientes estimados, os sinais esperados dos parâmetros associados aos desvios de despesas e arrecadação, são $\beta<0$ e $\gamma>0$, respectivamente. A condição de sustentabilidade ou solvência é dada por $\alpha>0$, indicando que existe uma resposta positiva em termos de geração de superávit primário depois de observado um aumento no acúmulo da dívida previdenciária no período anterior. Observe que a especificação da resposta fiscal em (4) não permite a possibilidade de presença de quebras estruturais. Assim, visando incorporar endogenamente as mudanças de regime existentes, estima-se a generalização de (4) expressa da seguinte forma:

$$
s p_{t}=\sum_{i=1}^{m+1}\left(\mu_{i}+\alpha_{i} e d p_{t-1} I_{t \in I_{i}}\right)+\beta \widetilde{d p_{t}}+\gamma \widetilde{r p}{ }_{t}+\varepsilon_{t}
$$


Observe que a relação (4) é um caso particular de (5), para $\mathrm{m}=0$, em que não haja quebras estruturais. Os resultados da estimação de (4) e (5) estão respectivamente nas Tabelas 4 e 5.

Mais especificamente, esta generalização se dá de forma que $I_{j}$ é o subperíodo determinado pelas quebras estruturais $t_{i-1}$ e $t_{i}$, e It $\in_{\mathrm{I} i}$ corresponde à função indicadora que assume valor 1 se $t_{\mathrm{i}-1} \leq \mathrm{t} \leq t_{i} \mathrm{e} 0$ caso contrário. Assim, para cada subperíodo $i$ temos um intercepto $\mu_{i}$ e uma condição de sustentabilidade associada ao sinal de $\alpha_{i}$, enquanto os parâmetros $\beta$ e $\gamma$ permanecem únicos e definidos sempre a partir da amostra completa, sendo mantida a intuição a respeito dos sinais destes parâmetros. Portanto, a estimação da resposta fiscal (5) é feita considerando-se subperíodos amostrais de acordo com a verificação de quebras estruturais nos parâmetros e , seguindo a proposta de Bai (1997) e Bai \& Perron (1998), de forma que os testes de quebra verificam se estão sendo realizados ajustes na política fiscal do governo a partir do relacionamento entre dívida e resultado primário. Dentre as técnicas de identificação endógena de quebras estruturais, faz-se uso aqui uso do procedimento proposto em Bai \& Perron (1998), o qual não exige ausência de tendência dos regressores, além de permitir múltiplas quebras a serem estimadas conjuntamente através do algoritmo descrito em Perron (1997). ${ }^{5}$

\section{Exercício Empírico}

\subsection{Base de Dados}

Os dados utilizados neste artigo consistem em rubricas previdenciárias, tais como a arrecadação líquida, a despesa com benefícios e o saldo previdenciário, além da série do PIB. Todas estas variáveis possuem frequência mensal e são reportadas em termos de $\mathrm{R} \$$ constantes de dezembro de 2010, com base no INPC, índice de preços que tem maior relação com a cesta de consumo dos ativos e assistidos pelo Instituto Nacional de Seguro Social (INSS). Os dados da previdência foram extraídos do Ministério da Previdência e Assistência Social e o PIB oriundo do Banco Central do Brasil.

5 Ver o teste de quebra proposto em Andrews (1993) aplicado a modelos não lineares, construído para regressores sem tendência.

Est. Econ., São Paulo, vol. 43, n.2, p. 301-333, abr.-jun. 2013 
As variáveis foram obtidas para o período de 1990 a 2010, totalizando 252 observações. A escolha do ano de 1990 como inicial do período de análise se deve ao fato de neste ano ter sido criado o (INSS), órgão responsável pela administração das contribuições e benefícios do RGPS até os dias atuais. A arrecadação líquida, ou receita previdenciária, corresponde à soma dos recolhimentos das empresas e contribuintes previdenciários menos as transferências a terceiros, como por exemplo, o Serviço Nacional de Aprendizagem Industrial (SENAI), o Serviço Social da Indústria (SESI), dentre outros.

Ao grupo despesas previdenciárias estão arrolados os benefícios previdenciários, abrangendo as aposentadorias por idade, por tempo de contribuição e por invalidez, pensões por morte, auxílio-doença, salário maternidade, dentre outros, e os benefícios acidentários, que são os benefícios por motivo de acidente do trabalho.

Na Figura 2, estão reportadas estas séries mensais em razão do PIB para o período de análise.

Há uma inversão de receitas e despesas já na metade da década de 1990, onde se registrou o primeiro déficit previdenciário. Este padrão em que as despesas são superiores às receitas permanece até o final da amostra. Análogo padrão se evidencia quando a análise se dá a partir das mesmas séries de rubricas previdenciárias, porém não mais em razão do PIB, mas em termos per capita, considerando-se a população economicamente ativa. Em 2010, percebe-se que para cada potencial contribuinte do RGPS, há uma necessidade de financiamento mensal em torno de R\$100,00, quando em 1990, havia crédito de $\mathrm{R} \$ 150,00$.

Na ausência de um indicador oficial que mensure a dívida acumulada da previdência social no Brasil, propõe-se a composição de um índice de saldo previdenciário acumulado considerando os resultados mensais atualizados, seguindo a metodologia usualmente adotada por órgãos oficiais para a apuração da necessidade de financiamento. O saldo previdenciário acumulado não representa apenas dívida, mas sim resultado, ou seja, seus valores são expressos por sinais positivos, quando indica uma posição superavitária, e negativos, em que representa a atual situação deficitária. 


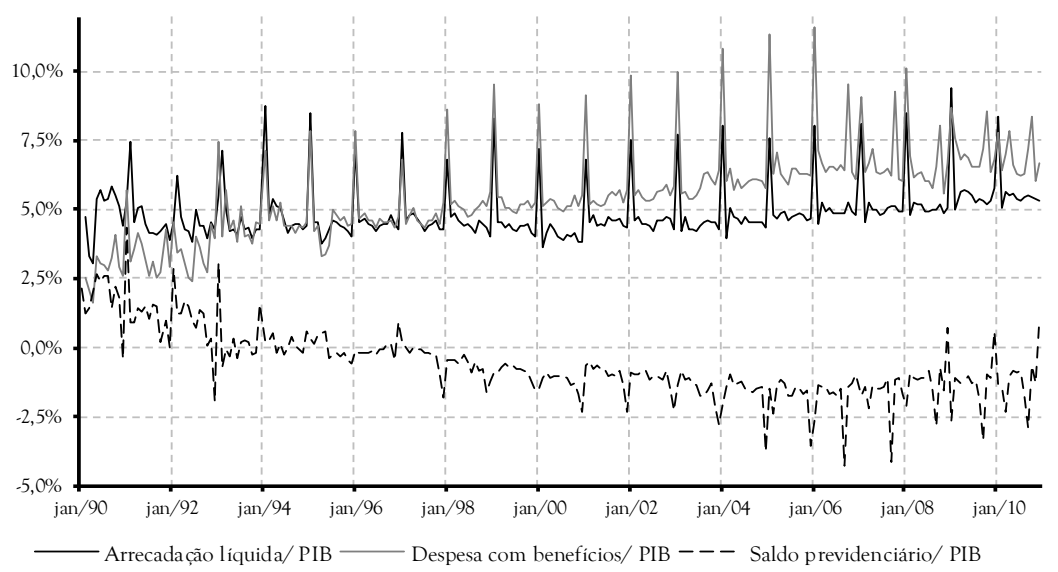

Figura 2 - Receita líquida, despesa e saldo previdenciário em razão do PIB ${ }^{\text {a, b }}$

a Valores das rubricas previdenciárias e do PIB expressos em reais constantes, atualizados pelo INPC mensal, a preço de dezembro/2010 (série temporal de janeiro de 1990 a dezembro de 2010, 252 observações mensais).

b Fonte: Ministério da Previdência Social (MPS) e Banco Central do Brasil (BACEN).

Na Figura 3, está reportada a série do saldo acumulado ponderado, correspondente ao valor negativo do estoque ponderado da dívida, $e d p$.

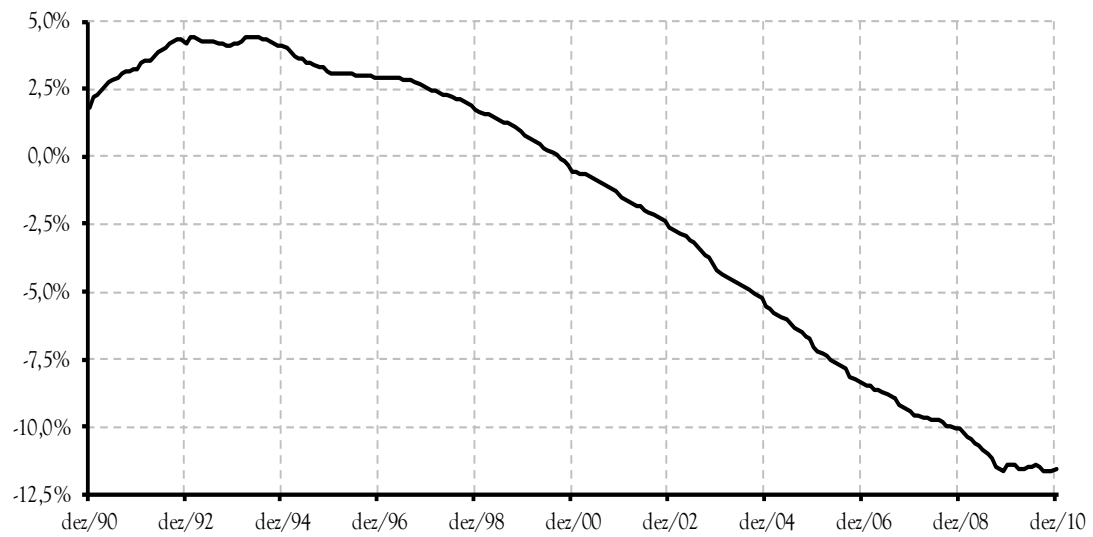

Figura 3 - Saldo previdenciário acumulado/ PIB acumulado nos últimos 12 meses

a Valores das rubricas previdenciárias e do PIB expressos em reais constantes, atualizados pelo INPC mensal, a preço de dezembro/2010 (série temporal de janeiro de 1990 a dezembro de 2010, 252 observações mensais).

b Fonte: Ministério da Previdência Social (MPS) e Banco Central do Brasil (BACEN). 
É possível identificar um comportamento ascendente somente até 1994, quando passa a haver mais frequentemente déficits previdenciários implicando uma trajetória constantemente decrescente, promovendo um acúmulo de dívida a qual assume valores superiores a $10 \%$ do PIB anual. A partir de 2006 o comportamento aparentemente linear parece suavizar em uma trajetória convexa, sinalizando certa estabilidade na evolução deste indicador da necessidade de financiamento, porém sem que se possa inferir sobre a sustentabilidade do regime.

\subsection{Estatísticas Descritivas}

A Tabela 2 reporta algumas estatísticas descritivas relevantes das séries mensais ajustadas de arrecadação líquida ou receitas e despesas previdenciárias, bem como do PIB, de 1990 a 2010.

Tabela 2 - Estatísticas descritivas das principais séries macroeconômicas e previdenciárias ${ }^{\mathrm{a}, \mathrm{b}}$

\begin{tabular}{lccc}
\hline & Arrecadação líquida & $\begin{array}{c}\text { Despesa com benefícios } \\
\text { previdenciários }\end{array}$ & PIB \\
\cline { 2 - 4 } Métrica & $\begin{array}{c}\text { Unidade: bilhões de } \mathrm{R} \$ \\
\text { constantes de dez/2010, } \\
\text { com base no INPC) }\end{array}$ & $\begin{array}{c}\text { Unidade: bilhões de } \mathrm{R} \$ \\
\text { constantes de dez/2010, } \\
\text { com base no INPC) }\end{array}$ & $\begin{array}{c}\text { Unidade: bilhões de } \mathrm{R} \$ \\
\text { constantes de dez/2010, } \\
\text { com base no INPC) }\end{array}$ \\
\cline { 2 - 4 } Média & $\mathrm{R} \$ 9,93$ & $\mathrm{R} \$ 11,66$ & $\mathrm{R} \$ 199,17$ \\
Desvio padrão & $\mathrm{R} \$ 4,22$ & $\mathrm{R} \$ 5,99$ & $\mathrm{R} \$ 59,64$ \\
Coeficiente de variação & 0,4248 & 0,5140 & 0,2995 \\
Mínimo & $\mathrm{R} \$ 4,29$ & $\mathrm{R} \$ 2,51$ & $\mathrm{R} \$ 95,72$ \\
Máximo & $\mathrm{R} \$ 30,52$ & $\mathrm{R} \$ 28,58$ & $\mathrm{R} \$ 337,24$ \\
Taxa de crescimento & 3,316 & $3,701 \%$ & $0,528 \%$ \\
\hline
\end{tabular}

a Valores das rubricas previdenciárias e do PIB expressos em reais constantes, atualizados pelo INPC mensal, a preço de dezembro/2010 (série temporal de janeiro de 1990 a dezembro de 2010, 252 observaçốes mensais).

b Fonte: Ministério da Previdência Social (MPS) e Banco Central do Brasil (BACEN).

Uma primeira evidência preocupante está associada ao valor médio de receitas serem consideravelmente inferiores aos de despesas, as quais se mostram mais voláteis, tanto com base no desvio padrão, como no coeficiente de variação, mesmo apresentando menor amplitude. 
Com relação às taxas mensais de crescimento, a evolução das despesas com benefícios se dá de forma ligeiramente mais rápida que as receitas e ambas com ritmo de crescimento da ordem de seis vezes a taxa do PIB. Estas simples evidências parecem justificar a preocupação em relação à sustentabilidade no longo prazo do sistema previdenciário brasileiro.

\subsection{Resultados}

\subsubsection{Exercício Preliminar: Raiz Unitária e Cointegração}

Inicialmente, procede-se com o tratamento das séries ponderadas pelo PIB de arrecadação e despesas, sendo ambas ajustadas devido à existência de sazonalidade, ocasionadas principalmente pelo impacto nos fluxos nos meses de setembro e dezembro oriundos do $13^{\circ}$ salário, o qual passou a ser pago em duas parcelas iguais nestes dois meses a partir do exercício de 2006. O ajustamento das séries de fluxos correntes e mensais foi realizado pelo método X12-ARIMA com opção por efeito aditivo.

O primeiro teste preliminar consiste em analisar a estacionariedade na série mensal de déficit previdenciário corrente. Visando obter resultados robustos à mudança de técnicas faz-se uso de diferentes especificações de testes de estacionariedade, além da versão aumentada (ADF) do teste originalmente proposto em Dickey-Fuller (1979, 1981). Assim, os demais testes utilizados são: i) o arcabouço semiparamétrico sugerido em Phillips e Perron (1988), ii) o teste KPSS proposto em Kwiatkowski, Phillips, Schmidt e Shin (1992), e iii) o método desenvolvido em Elliot, Rothemberg e Stock (1996). ${ }^{6}$

Os resultados destes testes estão reportados na Tabela 3.

6 Em razão de lidar com o tamanho da série temporal, foi proposta por Perron e NG (1996) uma extensão de Phillis e Perron (1988). 
Tabela 3 - Resultado dos testes de estacionariedade do saldo previdenciário ${ }^{\text {a, b, c }}$

\begin{tabular}{lccc}
\hline & Hipótese nula & Output & Resultado \\
\hline \multirow{2}{*}{ Augmented Dickey-Fuller } & Presença de raiz & p-valor & Insolvência \\
& unitária & $(0,1212)$ & \\
Phillips-Perron (1988) & Presença de raiz & $p$-valor & Solvência \\
& unitária & $(0,0001)$ & \\
Kwiatkowski-Phillips-Schmidt-Shin (1992) & Estacionariedade & Estatística LM & Insolvência \\
& & $(1,6985)$ & \\
Elliott-Rothenberg-Stock (1996) & Presença de raiz & Estatística P & Solvência \\
\hline
\end{tabular}

a Valores das rubricas previdenciárias e do PIB expressos em reais constantes, atualizados pelo INPC mensal, a preço de dezembro/2010 (série temporal de janeiro de 1990 a dezembro de 2010, 252 observações mensais).

b Fonte: Ministério da Previdência Social (MPS) e Banco Central do Brasil (BACEN).

${ }^{c}$ Especificação do teste: inclusão apenas de intercepto.

Os testes ADF e KPSS sugerem uma tendência explosiva da variável, sugerindo a insustentabilidade do sistema previdenciário, enquanto os outros dois rejeitam a hipótese nula de presença de raiz unitária, indicando sustentabilidade do regime previdenciário. Estes testes, apesar de clássicos, possuem especificações tais que apresentem distintos níveis de potência e inconsistência quando da análise de séries heterocedásticas, extraídas de pequenas amostras temporais ou mesmo que possuam quebras estruturais.

O segundo exercício preliminar está associado ao teste de cointegração das séries de arrecadação e despesa, a partir da técnica de Johansen (1991, 1995) baseada na estimação do Vetor Autorregressivo (VAR), a qual permite identificar a quantidade de vetores de cointegração existentes entre as variáveis.

A Tabela A.l. (apêndice) traz os resultados da estimação do VAR, a partir do uso de 4 lags, como sugerido pelo critério de Schwarz. ${ }^{7}$ A especificação do modelo parece adequada, pois o poder de explicação é superior a $85 \%$ e a maioria das variáveis explicativas é significativa a $5 \%$, exceto pelos valores mais defasados da arrecadação ao tentarem explicar as despesas previdenciárias, resultado

7 O Critério de Schwarz maximiza a probabilidade de escolha do verdadeiro modelo que descreva a relação entre as variáveis envolvidas, dentre os diversos modelos analisados. 
este corroborado pela significância conjunta associada aos valores da estatística $F$. As 8 raízes do polinômio associado ao VAR assumem valores dentro do círculo unitário, sinalizando a estabilidade do arcabouço estimado, cujo único fim se destina a dar suporte ao teste de Johansen, cujos resultados obtidos sugerem pelo menos uma relação de cointegração com intercepto e tendência entre as séries e até duas com tendência quadrática. Os valores da estatística do traço são corroborados pela estatística do máximo autovalor. A conclusão com base neste teste, portanto, valida a hipótese de que o saldo da previdência não deva seguir uma tendência explosiva.

Em ambos os exercícios, como um teste de robustez, foram efetuados os mesmos testes, porém levando-se em consideração as rubricas previdenciárias ponderadas pela população economicamente ativa, motivadas pela forte relação que as variáveis previdenciárias guardam com esta. No geral, os resultados apresentados ratificam as suposições anteriores, exceto pela inexistência de cointegração entre receitas e despesas. Analisando-se o saldo previdenciário acumulado, constatou-se estacionariedade, o que sugere uma tendência sustentável de longo prazo para o sistema. Assim, visivelmente, os resultados obtidos nestes testes preliminares são contraditórios e pouco conclusivos. Além disso, com base em Bohn (2007), a sustentabilidade evidenciada no teste de raiz unitária, assim como no teste de cointegração seria de caráter suficiente, mas não necessário, podendo haver solvência, mesmo quando estes testes rejeitam tal cenário, motivando uma análise mais criteriosa econometricamente.

Outro aspecto fundamental está relacionado ao fato de que ocorreram reformas no RGPS desde 1990, as quais podem ter promovido mudanças no padrão das variáveis previdenciárias, implicando mudanças de regimes ou quebras estruturais, aspecto não incorporado até então. Neste contexto, na subseção seguinte, são apresentados os resultados do principal exercício empírico aqui proposto.

\subsubsection{Função de Resposta Fiscal}

O arcabouço de resposta fiscal proposto em Bohn $(1998,2007)$ em sua versão sem quebras estruturais visa agregar na análise de solvência, captando a resposta positiva ou negativa na geração de superávit

Est. Econ., São Paulo, vol. 43, n.2, p. 301-333, abr.-jun. 2013 
primário no período corrente, dado um choque na dívida pública no período anterior.

Com relação ao tratamento sazonal das séries neste arcabouço de resposta fiscal, indispensável nos testes preliminares, o mesmo não foi adotado neste mesmo arcabouço. Ressalta-se que a variável 'saldo previdenciário' mensal é o resultado da diferença de duas séries, apresentando assim um efeito compensador que as variáveis em desvios também sofrem efeito compensatório em sua apuração e que o saldo previdenciário acumulado é uma variável do tipo estoque e não fluxo, sendo desnecessária sua transformação.

Além disso, o modelo permite a presença de quebras estruturais, de forma que caso a característica sazonal das séries seja relevante, o modelo é capaz de identificá-la. Assim, inicialmente, estima-se a relação (4) para o RGPS brasileiro, ainda sem mudança de regimes, cujos resultados estão reportados na Tabela 4 .

O arcabouço possui um poder de explicação superior a $55 \%$, sendo todos os parâmetros significativos a $5 \%$ individual e conjuntamente. As respostas aos desvios de arrecadação e despesa, $\gamma$ e $\beta$, respectivamente, são positivo e negativo, e o intercepto negativo, em acordo com as estatísticas descritivas reportadas na Tabela 1 . A conclusão mais importante consiste na redução do superávit em $t$, quando de um aumento em $t-1$ da dívida previdenciária acumulada, ou seja, $\alpha<0$, uma evidência de insolvência do RGPS no Brasil durante o período de 1990 a 2010.

Tabela 4 - Resultado da estimação do arcabouço da função resposta fiscal sem mudanças de regimes ${ }^{a}, \mathrm{~b}, \mathrm{c}$

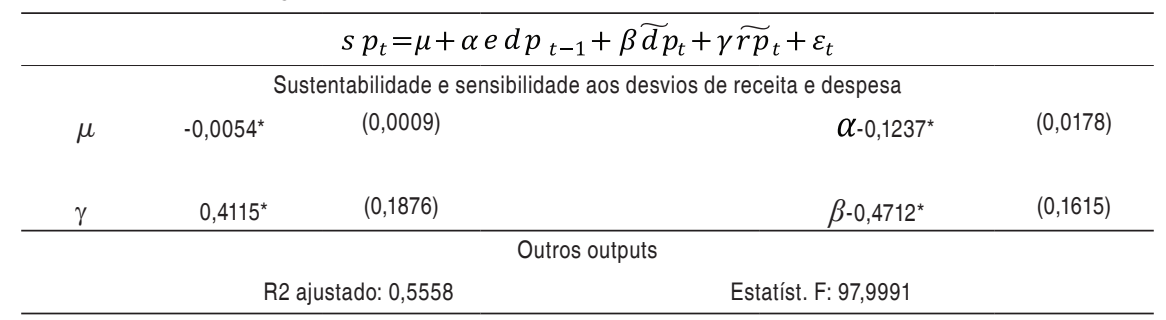

a Valores das rubricas previdenciárias e do PIB expressos em reais constantes, atualizados pelo INPC mensal, a preço de dezembro/2010 (série temporal de fevereiro de 1991 a dezembro de 2010, 239 observações mensais).

b Fonte: Ministério da Previdência Social (MPS) e Banco Central do Brasil (BACEN).

c Erro padrão reportado entre parênteses.

* Parâmetro significativo a 5\%. 
Uma limitação do arcabouço aqui proposto reside na proxy de dívida previdenciária proposta. Esta variável tem sua primeira mensuração a partir de janeiro de 1990. Sendo necessário no seu cálculo dividir pelo PIB dos últimos 12 meses, a mesma passa a estar disponível apenas a partir de dezembro de 1990. Apesar da escolha da série temporal estar associada à criação do INSS, estatisticamente, esta hipótese de que o estoque era nulo até então, pode afetar a estimação apenas do intercepto do arcabouço.

A limitação mais restritiva do arcabouço descrito pela relação (4) é comum a todas as técnicas de sustentabilidade previamente descritas: a incapacidade de incorporar mudanças de regimes ao longo do tempo. Neste sentido, estima-se a resposta fiscal generalizada (5), subperíodos amostrais de acordo com a verificação de quebras estruturais endógenas nos parâmetros $\mu$ e $\alpha$, seguindo a proposta de Bai (1997) e Bai e Perron (1998). Com relação à quantidade de regimes, o critério de Schwarz modificado (LWZ) proposto por Liu et al. (1997) sugere duas quebras estruturais, enquanto o critério Bayesiano (BIC) indica uma quebra a mais. A Tabela 5 reporta os resultados dos testes estatísticos associados aos critérios de informação usados na definição da quantidade de quebras, enquanto os resultados reportados na Tabela 6 seguem a especificação sugerida pelo critério BIC.

O arcabouço com a identificação de quebras (5) possui poder de explicação de $83 \%$, bastante superior aos $56 \%$ do arcabouço (4). Com relação aos coeficientes associados aos desvios de receita e despesa, estes possuem o mesmo sinal e valores próximos aos já obtidos quando da estimação sem quebras, os quais estão reportados na Tabela 4. No que se refere à solvência, ao longo de todo o período analisado, a tendência do saldo previdenciário parece ser decrescente. Analisando os regimes, observa-se que os valores iniciais para o saldo previdenciário são na grande maioria do tempo positivos, com exceções pontuais, como o elevado déficit em dezembro de 1992, implicando o único trecho ascendente do saldo acumulado ponderado pelo PIB dos últimos 12 meses, conforme Figura 3. O arcabouço identifica endogenamente uma primeira quebra em março de 1994, período que retrata um cenário em que o saldo previdenciário acumulado atingia um máximo local, com aproximadamente 4,39\% do PIB, caracterizando até mesmo visualmente um período de sustentabilidade. 
Na sequência, inicia-se uma série de saldos acumulados ainda positivos, porém com tendência decrescente. Durante o período entre a primeira quebra e outubro de 1997, quando o saldo representava 2,72\% do PIB, o arcabouço estimado sugeriu haver insolvência do RGPS, dado que $\alpha_{2}<0$, resultado que pode ser associado à sucessão de déficits previdenciários, uma vez que neste período, em mais de $65 \%$ dos meses, as despesas com benefícios superaram as receitas.

Tabela 5 - Resultado dos testes de especificação da quantidade de quebras do arcabouço de resposta fiscal ${ }^{\mathrm{a}, \mathrm{b}}$,

\begin{tabular}{ccc}
\hline \multirow{2}{*}{ Quantidade de quebras } & \multicolumn{2}{c}{ Critério de Informação } \\
\cline { 2 - 3 } & BIC & LWZ \\
\hline 0 & $-9,8876$ & $-9,8792$ \\
1 & $-10,3858$ & $-10,2999$ \\
2 & $-10,6400$ & $-10,4766$ \\
3 & $-10,6625$ & $-10,4213$ \\
4 & $-10,6087$ & $-10,2896$ \\
5 & $-10,5490$ & $-10,1518$ \\
\hline
\end{tabular}

a Série temporal de fevereiro de 1991 a dezembro de 2010, 239 observações mensais.

b Os testes usados

Após outubro de 1997 é possível observar sistematicamente déficits previdenciários mensais correntes, com raras exceções no final da amostra. No entanto, a evolução do agora déficit acumulado passa a ser linear e menos preocupante, principalmente após a terceira quebra estrutural em setembro de 2006, quando parece haver mudança da concavidade desta curva, conforme Figura 3.

Nos últimos dois regimes, as estimativas positivas para $\alpha_{3}$ e $\alpha_{4}$ sugerem haver solvência do sistema previdenciário, principalmente no quarto regime, quando este parâmetro assume seu maior valor absoluto. A análise das elasticidades saldo-dívida acumulada permite evidenciar um primeiro regime solvente, mas com baixa elasticidade, porém um segundo regime insolvente e com elasticidade de 1,64. O terceiro e o quarto regimes, ambos solventes, possuem elasticidades de 0,07 e 1,10 , respectivamente, sinalizando uma reação mais forte no controle de déficits previdenciários em resposta a um aumento da dívida previdenciária acumulada somente no regime mais recente. 
Verifica-se ainda que, a partir de 2006, são registradas taxas de crescimento das receitas superiores às das despesas, $4,50 \%$ e $2,73 \%$, respectivamente, tendo sido o desempenho registrado pela arrecadação líquida determinante para a desaceleração do ritmo de crescimento da necessidade de financiamento nos últimos anos.

Esta evidência, além da mudança de concavidade e da forte elasticidade associadas ao quarto regime podem estar associadas ao encerramento da primeira fase do Censo Previdenciário e a criação do Super Simples.

Tabela 6 - Resultado da estimação do arcabouço da função resposta fiscal com três mudanças de regimes ${ }^{\text {a, b, c }}$

$s p_{t}= \begin{cases}\mu_{1}+\alpha_{1} e d p_{t-1}+\beta \widetilde{d p_{t}}+\gamma \widetilde{r p_{t}}+\varepsilon_{t}, & 02 / 91 \leq t \leq 03 / 94 \\ \mu_{2}+\alpha_{2} e d p_{t-1}+\beta \widetilde{d p_{t}}+\gamma \widetilde{r p}_{t}+\varepsilon_{t}, & 04 / 94 \leq t \leq 10 / 97 \\ \mu_{3}+\alpha_{3} e d p_{t-1}+\beta \widetilde{d p_{t}}+\gamma \widetilde{r p}_{t}+\varepsilon_{t}, & 11 / 97 \leq t \leq 09 / 06 \\ \mu_{4}+\alpha_{4} e d p_{t-1}+\beta \widetilde{d p_{t}}+\gamma \widetilde{r p_{t}}+\varepsilon_{t}, & 10 / 06 \leq t \leq 12 / 10 \\ \hline\end{cases}$

Sustentabilidade - subamostra: 02/1991 a 03/1994, 38 obs.

$\begin{array}{llllll}\mu_{1} & 0,0314^{*} & (0,0041) & \alpha_{1} & 0,0104^{*} & (0,0005)\end{array}$

Sustentabilidade - subamostra: 04/1994 a 10/1997, 43 obs.

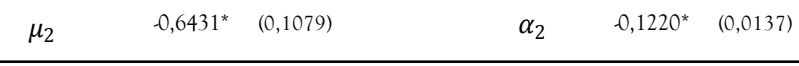

Sustentabilidade - subamostra: 11/1997 a 09/2006, 107 obs.

\begin{tabular}{llllll}
$\mu_{3}$ & 0,0073 & $(0,0042)$ & $\alpha_{3}$ & $0,0298^{*}$ & $(0,0056)$ \\
\hline
\end{tabular}

Sustentabilidade - subamostra: 10/2006 a 12/2010, 51 obs.

\begin{tabular}{cccccc}
$\mu_{4}$ & 0,1939 & $(0,1204)$ & $\alpha_{4}$ & $0,1570^{*}$ & $(0,0547)$ \\
\hline \multicolumn{5}{c}{ Sensibilidade aos desvios de receita e despesa } \\
$\gamma$ & $0,4364^{*}$ & $(0,0414)$ & $\beta$ & $-0,4788^{*}$ & $(0,0311)$ \\
\hline \multicolumn{4}{c}{ Outros outputs }
\end{tabular}

$\mathrm{R}^{2}$ ajustado: $0,8330 \quad$ Estatíst. $\mathrm{F}(10,229): 114,6290$

a Valores das rubricas previdenciárias e do PIB expressos em reais constantes, atualizados pelo INPC mensal, a preço de dezembro/2010 (série temporal de fevereiro de 1991 a dezembro de 2010, 239 observações mensais).

b Fonte: Ministério da Previdência Social (MPS) e Banco Central do Brasil (BACEN).

c Erro padrão reportado entre parênteses. * Parâmetro significativo a 5\%. 


\subsubsection{Análise de Robustez dos Resultados da Função de Resposta Fiscal}

Em termos de robustez, é válido analisar a especificação com apenas duas quebras. Ambos os critérios de informação são consistentes assintoticamente, porém, segundo Bai \& Perron (2001), seria possível identificar uma melhor performance de critério LWZ em relação ao BIC, o que motivaria a estimação do arcabouço com apenas duas quebras. Nesta nova especificação, a primeira mudança se daria em maio de 1995 e a segunda em janeiro de 2006. Corroborando os resultados anteriores, há evidência de insolvência somente até 1995, sendo sustentável daí em diante. Os sinais dos demais coeficientes não sofrem alteração e o valor do coeficiente associado à dívida previdenciária acumulada no período de insolvência passa de $-0,1220$ para $-0,1665$. Os resultados deste teste de robustez estão na Tabela A.2 (apêndice).

Por fim, como um segundo teste de robustez, estima-se uma última especificação, na qual cada variável fluxo é dessazonalizada. Analisando-se a série completa, sem quebras estruturais, o resultado de insustentabilidade permanece e incorporando-se a possibilidade de mudanças endógenas, observa-se novamente a mesma quantidade de regimes, em datas similares ou bastante próximas, sinais de parâmetros idênticos, com estimativas sem maiores alterações na ordem de grandeza. Estes resultados estão na Tabela A.3. (apêndice).

\section{Conclusão}

O Regime Geral de Previdência Social no Brasil é regido por um sistema de repartição simples e está bastante fora do padrão internacional, em termos de regras, demografia, incentivos e base contributiva.

Este panorama já preocupante se agravou em 1995, com o crescimento das despesas com benefícios do RGPS originado pelo advento da Lei $n^{\circ} 8.213 / 91$, em que se determinou a padronização dos benefícios urbanos e rurais, com o aumento do universo de beneficiários, com a crise econômica e com a política de concessão de ganhos reais do salário mínimo, cujo impacto é positivo em ambas as rubricas previdenciárias, arrecadação e despesas, porém com maior elasticidade nas despesas, segundo Dantas, Ataliba \& Matos (2012). Em acordo com os resultados obtidos por estes autores, com base nos valores 
do ano de 2010, um aumento em 1\% ao mês no salário mínimo real, equivalente a $\mathrm{R} \$ 5,25$, implicaria um aumento no déficit anual em R \$ 830 milhões. Visando compensar um desajuste previdenciário desta magnitude, bastaria que o governo obtivesse, ceteris paribus, um crescimento do PIB superior a 0,62\% ao mês, o que equivale a um crescimento da economia superior ao patamar de 7,5\% ao ano. Em contrapartida, os principais fatos que amenizaram este cenário parecem ter sido o encerramento da primeira fase do Censo Previdenciário e a criação do Super Simples em 2005. Este censo teve como objetivo a atualização cadastral do INSS e a consequente eliminação de benefícios pagos indevidamente, enquanto o Super Simples fomentou a expectativa de incremento na arrecadação, em virtude de um possível aumento nas relações formalizadas de trabalho em setores não alcançados pelo sistema de arrecadação que substituiu, mesmo podendo haver uma possível perda em razão de renúncia fiscal.

Vale lembrar que esta significativa alocação do PIB em previdência, apesar de demonstrar melhoria no atendimento das questões sociais, é onerosa quando representa a não aplicação de recursos em atividades geradoras de retornos mais expressivos ao crescimento do país. Uma vez que há um custo fiscal considerável para a sociedade, pois quando o regime apresenta déficit, este é financiado pelo Governo, torna-se imprescindível ponderar se este sistema é capaz de apresentar reações positivas na tentativa de equilibrar-se por conta própria, ou ao menos reduzir sua dependência do estado.

Neste contexto, através do arcabouço proposto em Bohn $(1998,2007)$, é possível identificar, seguindo Bai (1997) e Bai \& Perron (1998), que o saldo previdenciário do RGPS brasileiro apresenta quatro distintos regimes durante janeiro de 1990 e dezembro de 2010, sendo apenas um deles caracterizado como insolvente, durante abril de 1994 e outubro de 1997. Assim, ao contrário do que diversas análises apontam sobre a situação do RGPS, os resultados revelam uma trajetória recente não explosiva para a previdência social brasileira. Entretanto, verificase que a adoção de novas reformas é imprescindível para a reversão do quadro deficitário, fato ratificado pela evolução obtida com as medidas adotadas em 2006. A necessidade de reformas já foi apontada em diversos estudos, principalmente no que diz respeito a não associação do piso previdenciário ao salário mínimo, adoção da idade mínima para aposentadoria e implantação de políticas que busquem o aumento da formalização nas relações de emprego. Reformas paramétricas trazem avanços ao equilíbrio financeiro e da previdência social, mas podem 
não ser eficazes no longo prazo, dado que as receitas e despesas previdenciárias são sujeitas a inúmeras variáveis em constante mutação.

A constatação aqui obtida sugere que o país possui um comportamento estacionário de suas contas, o que pode representar um avanço na discussão do processo de adoção de reformas estruturais. Trabalhos como Sousa (2009) também apontam, segundo determinados cenários, para a estabilização do déficit e até conversão para uma situação superavitária. Contudo, pensar em reformas estruturais requer um esforço fiscal elevado, e a estabilidade do saldo previdenciário não é garantia de que o orçamento público poderia suportá-lo. Neste sentido, faz-se necessário a mensuração do custo de transição e respostas às questões que permeiam o financiamento dos atuais assistidos e a como fundar os futuros benefícios.

\section{Referências}

ANDREWS, D. Tests for parameter instability and structural change with unknown change point. Econometrica, 61, 821-56, 1993.

BAI, J. Estimating multiple breaks one at a time. Econometric Theory, 13, 315-52, 1997.

e PERRON, P. Estimating and testing linear models with multiple structural changes. Econometrica, 66, 47-78, 2001. Computation and analysis of multiple structural change models. Journal of Applied Econometrics, 18, 1-22, 1998.

BOHN, H. Budget balance through revenue or spending adjustments? Some historical evidence for the United States. Journal of Monetary Economics. 27, 333-359, 1991.

The behavior of U.S. public debt and deficits. Quarterly Journal of Economics, 113, 949-63, 1998. Are stationarity and cointegration restrictions really necessary for the intertemporal budget constraint? Journal of Monetary Economics, 54, 1837-1847, 1998.

CAETANO, M. Determinantes da Sustentabilidade e do Custo Previdenciário: Aspectos Conceituais e Comparações Internacionais. IPEA, Texto para discussão $n^{\circ}$ 1226, 2006.

CAETANO, M. e MIRANDA, R. Comparativo Internacional para a Previdência Social. IPEA, Texto para discussão $n^{\circ} 1302,2007$.

CUSINATO, R., MINELLA, A. e PÔRTO Jr., S. Produção Industrial no Brasil: uma análise de dados em tempo real. Working Paper Series Banco Central do Brasil, n.209, 2010.

DANTAS, E. ATALIBA, F. E MATOS, P. Regime geral da previdência social no Brasil: modelagem, previsão e cenários. Working paper, CAEN-UFC, 2012.

DICKEY, D. E WAYNE, F. Distribution of the Estimators for Autoregressive Time Series With a Unit Root. Journal of the American Statistical Association, 74, 427-431, 1979.

DICKEY, D. e WAYNE, F. Likelihood ratio statistics for autoregressive time series with a unit root. Econometrica , 49, 1057-1072, 1979.

ELLIOTT, G., ROTHENBERG, T. e STOCK, J. Efficient Tests for an Autoregressive Unit Root. Econometrica, 64, 813-36, 1996.

ENGLE, R. e GRANGER, C. Co-integration and error correction: representation, estimation, and testing, Econometrica, 55, 251-276, 1987.

Est. Econ., São Paulo, vol. 43, n.2, p. 301-333, abr.-jun. 2013

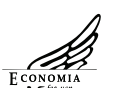


GARCIA, M. e RIGOBON, F. A Risk Management Approach to Emerging Market's Sovereign Debt Sustainability with an Application to Brazilian Data. NBER Working Paper 10336. Cambridge, MA, 2004.

GIAMBIAGI, F., ZYLBERSTAJN, H., AFONSO, L., SOUZA, A. e ZYLBERSTAJN, E. Impacto de Reformas Paramétricas Na Previdência Social Brasileira: Simulações Alternativas. Revista Pesquisa e Planejamento Econômico, 37, 175-219, 2007.

HAMILTON, J. e FLAVIN, M. On the limitations of government borrowing: a framework for empirical testing. American Economic Review, 76, 808-819, 1986.

JOHANSEN, S. Estimation and hypothesis testing of cointegration vectors in Gaussian vector autoregressive models. Econometrica, 59, 1551-1580, 1991. Likelihood-based inference in cointegrated vector autoregressive models. Oxford: Oxford University Press, 1995.

HAKKIO, C. e RUSH, M. Is the budget deficit "too large"? Economic Inquiry, 29, 429-445, 1991.

KWIATKOWSKI, D., PHILLIPS, P., SCHMIDT, P. e SHIN, Y. Testing the null hypothesis of stationarity against the alternative of a unit root: How sure are we that economic time series have a unit root? Journal of Econometrics, 54, 159-178, 1992.

LEITE, A., NESS, W. e KLOTZLE, M. Previdência Social: fatores que explicam os resultados financeiros. Revista de Administração Pública, 44, 437-457, 2010.

LIU, J., WU. S. e ZIDEK, J. On segmented multivariate regression. Statistical Sinica, 7, 497-525, 1997.

LUPPORINI, V. Further Investigation Into The Sustainability of The Brazilian Federal Domestic Debt. Texto para Discussão n.131, UFMG/Cedeplar, 2000.

MASCARENHAS, R., OLIVEIRA, A. e CAETANO, M. Análise atuarial da reforma da previdência do funcionalismo público da União. MPS/SPS. Coleção Previdência social, Vol. 21, 2004.

OLIVEIRA, F., BELTRÃO, K., PINHEIRO, K., PEYNEAU, F. e MENDONÇA, J. O Idoso e a Previdência Social. Texto para Discussão, $n .^{\circ} 413$, IPEA. 1999.

OLIVEIRA, F., BELTRÃO, K. e FERREIRA, M. The Brazilian social security system. Texto para discussão, $n .^{\circ} 775$, IPEA, 2000.

OLIVEIRA, F., BELTRÃO, K. e PASINATO, M. Reforma estrutural da previdência: uma proposta para assegurar proteção social e eqüidade. Texto para discussão, $n .^{\circ}$ 609. IPEA, 1999.

PASTORE, A. Déficit Público, a Sustentabilidade do Crescimento das Dívidas Interna e Externa, Senhoriagem e Inflação: Uma Análise do Regime 60 Monetário Brasileiro. Revista de Econometria, 14, 177-234, 1995.

PEREIRA, J. Sustentabilidade da dívida pública dos estados brasileiros. Dissertação de Mestrado, CEDEPLAR-UFMG, 2008.

PERRON, P. e NG, S. Useful Modifications to Some Unit Root Tests with Dependent Errors and Their Local Asymptotic Properties. Review of Economic Studies, 63, 435-63, 1996.

PERRON, P. Further evidence on breaking trend functions in macroeconomic variables. Journal of Econometrics, 80, 355-385, 1997.

PHILliPS, P. e PERRON, P. Testing for a Unit Root in Time Series Regression. Biometrika, 75, 335-346, 1988.

RAMOS, A. Uma Introdução ao Estudo dos Novos Institutos da Previdência Complementar no Brasil. Monografia de Graduação apresentada ao Curso de Ciências Atuariais da Universidade Federal do Ceará, 2003.

ROCHA, F. Long-run limits on the Brazilian government debt. Revista Brasileira de Economia, 51, 447-470, 1997.

SIMONASSI, A., e ARRAES, R. Função de Resposta Fiscal, Múltiplas Quebras Estruturais e a Sustentabilidade da Dívida Pública no Brasil. Anais do XXXV Encontro Nacional de Economia da ANPEC, Recife-PE, 2007. 
SOUZA, A., ZYLBERSTAJN, H., AFONSO, L. e FLORI, P. Resultados Fiscais da Reforma de 2003 no Sistema de Previdência Social Brasileiro. Pesquisa e Planejamento Econômico, 36, 1-37, 2006.

TAFNER, P. Simulando o desempenho do sistema previdenciário e seus efeitos sobre pobreza sob mudanças nas regras de pensão e aposentadoria. Texto para discussão, $n .^{\circ}$ 1264, IPEA, 2007.

UCTUM, M., THURSTON, T. e UCTUM R. Public Debt, the Unit Root Hypothesis and Structural Breaks: A Multi-Country Analysis. Economica, 73:129-156, 2006.

\section{Apêndice}

Tabela A.1. - Resultado da estimação do arcabouço VAR ${ }^{\text {a, b, c, d }}$

\begin{tabular}{|c|c|c|c|c|c|}
\hline \multirow{2}{*}{$\begin{array}{l}\text { Variável } \\
\text { exógena }\end{array}$} & \multicolumn{2}{|c|}{ Variável endógena } & \multirow{2}{*}{$\begin{array}{l}\text { Variável } \\
\text { exógena }\end{array}$} & \multicolumn{2}{|c|}{ Variável endógena } \\
\hline & $d p_{t}$ & $r p_{t}$ & & $d p_{t}$ & $r p_{t}$ \\
\hline$d p_{t-1}$ & $\begin{array}{l}0,4285^{*} \\
(0,0647)\end{array}$ & $\begin{array}{l}0,2104^{*} \\
(0,0609)\end{array}$ & $r p_{t-1}$ & $\begin{array}{l}0,1007^{*} \\
(0,0709)\end{array}$ & $\begin{array}{l}0,1229^{*} \\
(0,0667)\end{array}$ \\
\hline$d p_{t-2}$ & $\begin{array}{l}0,1901^{*} \\
(0,0687)\end{array}$ & $\begin{array}{l}-0,1516^{*} \\
(0,0647)\end{array}$ & $r p_{t-2}$ & $\begin{array}{l}-0,0641 \\
(0,0694)\end{array}$ & $\begin{array}{l}0,2681^{*} \\
(0,0653)\end{array}$ \\
\hline$d p_{t-3}$ & $\begin{array}{l}-0,0124 \\
(0,0694)\end{array}$ & $\begin{array}{l}-0,1383^{*} \\
(0,0653)\end{array}$ & $r p_{t-3}$ & $\begin{array}{l}-0,1444 \\
(0,0687)\end{array}$ & $\begin{array}{l}0,1927^{*} \\
(0,0646)\end{array}$ \\
\hline$d p_{t-4}$ & $\begin{array}{l}0,3464^{*} \\
(0,0634)\end{array}$ & $\begin{array}{l}0,1146^{*} \\
(0,0597)\end{array}$ & $r p_{t-4}$ & $\begin{array}{c}0,0469 \\
(0,0706)\end{array}$ & $\begin{array}{l}0,1310^{*} \\
(0,0664)\end{array}$ \\
\hline C & 0,0060 & $0,0122^{*}$ & $\mathrm{R}^{2}$ ajust. & 0,8555 & 0,3378 \\
\hline & & & Estatíst. F & 183,8218 & 16,7500 \\
\hline
\end{tabular}

a Valores das rubricas previdenciárias e do PIB expressos em reais constantes, atualizados pelo INPC mensal, a preço de dezembro/2010 (série temporal de maio de 1990 a dezembro de 2010, 248 observações mensais).

b Fonte: Ministério da Previdência Social (MPS) e Banco Central do Brasil (BACEN).

c Erro padrão reportado entre parênteses.

d Critério de Schwarz: 4 defasagens.

* Parâmetro significativo a 5\%. 
Tabela A.2. - Teste de robustez à mudança de regime: estimação do arcabouço da função resposta fiscal com duas mudanças de regimes ${ }^{a}$, b, c, d

$$
s p_{t}= \begin{cases}\mu_{1}+\alpha_{1} e d p_{t-1}+\beta \widetilde{d p}_{t}+\gamma \widetilde{r p}_{t}+\varepsilon_{t}, & 02 / 91 \leq t \leq 05 / 95 \\ \mu_{2}+\alpha_{2} e d p_{t-1}+\beta \widetilde{d p}_{t}+\gamma \widetilde{r p}_{t}+\varepsilon_{t}, & 06 / 95 \leq t \leq 01 / 06 \\ \mu_{3}+\alpha_{3} e d p_{t-1}+\beta \widetilde{d p_{t}}+\gamma \widetilde{r p}_{t}+\varepsilon_{t}, & 02 / 06 \leq t \leq 12 / 10\end{cases}
$$

Sustentabilidade - subamostra: 02/1991 a 05/1995, 52 obs.
$\mu_{1}$
$0,0331^{*} \quad(0,0040)$
$\alpha_{1} \quad-0,1665^{*}$
$(0,0130)$

Sustentabilidade - suba mostra: 06/1995 a 01/2006, 128 obs.
$\mu_{2}$
$-0,7092^{*}$
$(0,1037)$
$\alpha_{2} \quad 0,0303^{*}$
$(0,0043)$

Sustentabilidade - subamostra: 02/2006 a 12/2010, 59 obs.

$\begin{array}{llllll}\mu_{3} & 0,0091^{*} & (0,0004) & \alpha_{3} & 0,1605^{*} & (0,0439)\end{array}$

Sensibilidade aos desvios de receita e despesa

$\gamma \quad 0,4363^{*}(0,0431) \quad \beta \quad-0,4765^{*} \quad(0,0324)$

Outros outputs

$\mathrm{R}^{2}$ ajustado: 0,8180

Estatíst. F (8,231): 129,4240

a Valores das rubricas previdenciárias e do PIB expressos em reais constantes, atualizados pelo INPC mensal, a preço de dezembro/2010 (série temporal de fevereiro de 1991 a dezembro de 2010, 239 observações mensais).

b Fonte: Ministério da Previdência Social (MPS) e Banco Central do Brasil (BACEN).

c Erro padrão reportado entre parênteses.

d Quantidade de quebras sugerida pelo critério LWZ. * Parâmetro significativo a 5\%. 
Tabela A.3. - Teste de robustez à sazonalidade: estimação do arcabouço da função resposta fiscal com três mudanças de regime ${ }^{a, b, c}$

$$
s p_{t}= \begin{cases}\mu_{1}+\alpha_{1} e d p_{t-1}+\beta \widetilde{d p}_{t}+\gamma \widetilde{r p}_{t}+\varepsilon_{t}, & 02 / 91 \leq t \leq 12 / 93 \\ \mu_{2}+\alpha_{2} e d p_{t-1}+\beta \widetilde{d p}_{t}+\gamma \widetilde{r p}_{t}+\varepsilon_{t}, & 01 / 94 \leq t \leq 10 / 97 \\ \mu_{3}+\alpha_{3} e d p_{t-1}+\beta \widetilde{d p}_{t}+\gamma \widetilde{r p}+\varepsilon_{t}, & 11 / 97 \leq t \leq 09 / 06 \\ \mu_{4}+\alpha_{4} e d p_{t-1}+\beta \widetilde{d p}_{t}+\gamma \widetilde{r p}_{t}+\varepsilon_{t}, & 10 / 06 \leq t \leq 12 / 10 \\ \hline\end{cases}
$$

Sustentabilidade - subamostra: 02/1991 a 12/1993, 35 obs.
$\mu_{1}$
$0,0303^{*} \quad(0,0037)$
$\alpha_{1} \quad 0,0103^{*}$
$(0,0005)$

Sustentabilidade - subamostra: 01/1994 a 10/1997, 46 obs.

\begin{tabular}{llllll}
$\mu_{2}$ & $-0,6056^{*}$ & $(0,0988)$ & $\alpha_{2}$ & $-0,1248^{*}$ & $(0,0122)$ \\
\hline
\end{tabular}

Sustentabilidade - subamostra: 11/1997 a 09/2006, 107 obs.
$\mu_{3}$
$-0,0068$
$(0,0035)$
$\alpha_{3} \quad 0,0279^{*}$
$(0,0050)$

Sustentabilidade - subamostra: 10/2006 a 12/2010, 51 obs.
$\mu_{4}$
0,1786
$(0,1006)$
$\alpha_{4} \quad 0,1395^{*}$
$(0,0487)$

Sensibilidade aos desvios de receita e despesa
$\gamma$
$0,5525^{*} \quad(0,0680)$
$\beta$
$-0,2970^{*}$
$(0,0364)$

Outros outputs

$R^{2}$ ajustado: 0,8450

Estatíst. F (10,229): 125,2900

a Valores das rubricas previdenciárias e do PIB expressos em reais constantes, atualizados pelo INPC mensal, a preço de dezembro/2010 (série temporal de fevereiro de 1991 a dezembro de 2010, 239 observações mensais).

b Fonte: Ministério da Previdência Social (MPS) e Banco Central do Brasil (BACEN).

c Erro padrão reportado entre parênteses.

* Parâmetro significativo a 5\%. 